\title{
Manejo da água e nutrientes para o pepino em ambiente protegido sob fertirrigação
}

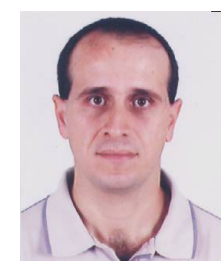

Flávio F. Blanco ${ }^{1} \&$ Marcos V. Folegatti²

\author{
1 Depto. de Engenharia Rural, USP/ESALQ. CP 9, CEP 13418-900, Piracicaba, SP. Fone: (19) 3429-4217, Ramal 268 \\ E-mail: ffblanco@carpa.ciagri.usp.br (Foto) \\ 2 Depto. Engenharia Rural, USP/ESALQ. Fone: (19) 3429-4380. E-mail: mvfolega@carpa.ciagri.usp.br
}

Protocolo $127-31 / 8 / 2001$

\begin{abstract}
Resumo: A fertirrigação é uma prática bastante utilizada em áreas irrigadas por gotejamento e em ambiente protegido, além de indispensável para a maximização dos benefícios desse sistema de cultivo. Neste trabalho tem-se os resultados obtidos em um cultivo de pepino em ambiente protegido, seguindo-se um esquema preestabelecido de fertirrigação e manejo combinado da lâmina de irrigação. A produtividade comercial foi superior a $110 \mathrm{Mg} \mathrm{ha}^{-1}$ e a 76 frutos $\mathrm{m}^{-2}$, muito acima da média obtida pelos produtores do Estado de São Paulo e daquelas apresentadas em diversos trabalhos nacionais. O manejo da fertirrigação adotado pode ser utilizado como referência para futuros trabalhos com esta cultura, em ambiente protegido.
\end{abstract}

Palavras-chave: Cucumis sativus, produção, potencial mátrico, lâmina de irrigação

\section{Management of water and nutrients for fertirrigated cucumber in a greenhouse}

\begin{abstract}
Fertigation is a practice that has been widely used in drip irrigated areas and in greenhouses. It is indispensable to maximize the benefits of the cropping system. In this study, results from a cucumber cultivation in a greenhouse, following a preset fertigation scheduling and a combined method for irrigation management are presented. Marketable crop yield was over $110 \mathrm{Mg} \mathrm{ha}^{-1}$ and 76 fruits $\mathrm{m}^{-2}$, which is much higher than that obtained by growers of this State and else where in Brazil. The management of fertigation adapted indicated that the same could be used as a reference for future cultivation under greenhouse conditions.
\end{abstract}

Key words: Cucumis sativus, crop yield, matric potential, water depth

\section{INTRODUÇÃO}

O pepino (Cucumis sativus L.) é uma das principais culturas exploradas em ambiente protegido, podendo-se obter frutos de excelente qualidade comercial, com aumento significativo na lucratividade, em comparação com o cultivo em campo. A aplicação de fertilizantes via água de irrigação é uma prática utilizada há muito tempo. Entretanto, a pesquisa sobre fertirrigação e as aplicações práticas aliadas aos avanços no dimensionamento de sistemas de irrigação levaram, recentemente, a uma rápida expansão desta técnica (Papadopoulos, 1999).

Para que a fertirrigação seja eficiente, é necessário um equilíbrio entre a quantidade de nutrientes e a quantidade de água a ser aplicada durante cada fase do ciclo da cultura, o que determina a concentração de fertilizantes na água de irrigação; por sua vez, esta concentração deve ser suficiente para proporcionar a absorção dos nutrientes nas quantidades requeridas pelas plantas, sem causar o acúmulo de fertilizantes no solo, o que poderia resultar em salinização e, conseqüentemente, na redução da produtividade. Para isto, é necessário que se conheça a quantidade de água a ser aplicada em cada irrigação, a qual pode ser determinada pelo uso de tensiômetros ou estimada a partir da lâmina de água evaporada do tanque Classe A, multiplicada pelo coeficiente da cultura $(\mathrm{Kc})$.

Apesar de poucos trabalhos de pesquisa publicados no Brasil em fertirrigação de hortaliças, esta prática é bastante difundida, principalmente entre horticultores que utilizam a irrigação por gotejamento e fazem uso de fórmulas e procedimentos desenvolvidos por consultores, nacionais ou estrangeiros, e firmas de fertilizantes ou produtos agrícolas que, muitas vezes, não atendem às necessidades das culturas (Silva et al., 1999).

Para nossas condições, existem alguns trabalhos realizados com a cultura do pepino em ambiente protegido. Para o cultivo em solo, Carneiro Jr. et al. (2000) obtiveram produção total da cultivar Hokuho de 2,12 kg por planta, sendo a produção comercial de 1,97 kg por planta. Delmanto Jr \& Saad (2000) trabalhando com esta mesma cultivar, obtiveram 39,58 frutos $\mathrm{m}^{-2}$ 
sendo 23,75 de qualidade comercial quando utilizaram o sistema de irrigação por gotejamento instalado na superfície do solo. Para a cultivar Hokushin, Faria Jr et al. (1998) obtiveram produtividade total e comercial de 12,93 e $9,37 \mathrm{~kg} \mathrm{~m}^{-2}$, respectivamente, sendo o número de frutos comerciais por planta de 23,9.

Acredita-se ter a enxertia em pepino começado em 1965, com o objetivo de se prevenir a ocorrência da doença causada por Fusarium oxysporum e nematóides (Cañizares, 1998). Temse informações de que no Estado de São Paulo a enxertia pode proporcionar um período de colheita de até $120 \mathrm{~d}$, sendo de 50 a 70 d, em média, para o pepino não enxertado (Blanco, 1999). Cañizares \& Goto (1998) obtiveram aumento na produtividade das cultivares Nikkey e Ancor, de 9,7 e 21,9\%, respectivamente, quando enxertadas sobre abóbora híbrida "Ikki", em relação às plantas não enxertadas. O número de frutos totais e comerciais por metro quadrado foi de 48,6 e 29,1 para Nikkey e de 52,9 e 40,3 para Ancor, respectivamente.

Objetivou-se, com este trabalho, comparar a produtividade do pepino enxertado obtida por Blanco (1999), com aquelas obtidas por outros autores, a fim de se verificar a adequação do esquema de manejo da água e nutrientes utilizado. Esperase que os resultados sirvam de referência para futuros trabalhos em ambiente protegido onde a fertirrigação dessa cultura se fizer necessária.

\section{MATERIAL E MÉTODOS}

O experimento foi conduzido na área experimental do Departamento de Engenharia Rural da Escola Superior de Agricultura "Luiz de Queiroz" - USP, no município de Piracicaba, SP, em um solo do tipo Terra Roxa Estruturada, série "Luiz de Queiroz", cujo material de origem são rochas básicas. As características físicas do solo estão apresentadas na Tabela 1.

Tabela 1. Propriedades físico-hídricas do solo*, em diferentes profundidades

\begin{tabular}{|c|c|c|c|c|c|c|c|}
\hline \multirow{2}{*}{$\begin{array}{l}\text { Prof. } \\
\text { m }\end{array}$} & Argila & Silte & Areia & $\theta_{\mathrm{S}}$ & $\theta_{\mathrm{CC}}$ & $\theta_{\mathrm{PMP}}$ & \multirow{2}{*}{$\begin{array}{c}\rho \\
\mathrm{Mg} \mathrm{m}^{-3}\end{array}$} \\
\hline & \multicolumn{3}{|c|}{$\mathrm{g} \mathrm{kg}^{-3}$} & \multicolumn{3}{|c|}{$\mathrm{cm}^{3} \mathrm{~cm}^{-3}$} & \\
\hline $0-0,2$ & 460 & 140 & 400 & 0,460 & 0,373 & 0,257 & 1,49 \\
\hline $0,2-0$ & 500 & 130 & 370 & 0,415 & 0,359 & 0,2 & 1,66 \\
\hline $0,4-0,6$ & 520 & 130 & 350 & 0,436 & 0,391 & 0,303 & 1,52 \\
\hline
\end{tabular}

$* \theta_{\mathrm{S}}$ - Umidade do solo saturado; $\theta_{\mathrm{CC}}$ - Umidade do solo na capacidade de campo; $\theta_{\mathrm{PMP}}$ - Umidade do solo no ponto de murcha permanente; $\rho$ - Densidade do solo

O ambiente protegido utilizado apresentava área total de $110 \mathrm{~m}^{2}$, pé direito $2,8 \mathrm{~m}$, com sombrite nas laterais e nos fundos. As laterais possuíam cortinas que eram abertas pela manhã e fechadas no final da tarde e na ocorrência de chuvas, para evitar que a água atingisse as parcelas experimentais. Foram construídos três canteiros de $16,65 \mathrm{~m}$ de comprimento e $1 \mathrm{~m}$ de largura, espaçados $1 \mathrm{~m}$, nos quais foram transplantadas mudas de pepino japonês, cultivar Hokushin, enxertado sobre Cucurbita spp., híbrido Excite-Ikki. O transplantio foi realizado no dia 23/6/1999, em filas duplas, no espaçamento de $0,70 \mathrm{~m}$ entre linhas, 0,40 m entre plantas e $1,30 \mathrm{~m}$ entre as filas duplas. As parcelas experimentais, compostas de 10 plantas, foram conduzidas por fitilhos e um arame instalado a $2 \mathrm{~m}$ de altura em cada linha de plantio.
Como neste experimento foram aplicadas águas de irrigação de diferentes níveis de salinidade, visando-se determinar a tolerância da cultura, avaliaram-se apenas os dados correspondentes aos tratamentos irrigados com água não salina, sob duas diferentes lâminas de irrigação: $\mathrm{L}_{1}=1,00 \mathrm{ETc}$ e $\mathrm{L}_{2}=1,25 \mathrm{ETc}$, sendo a ETc a evapotranspiração da cultura.

O manejo da irrigação foi realizado com base nas leituras de um tanque de evaporação reduzido, de 0,60 m de diâmetro e $0,25 \mathrm{~m}$ de altura, instalado no interior do ambiente protegido sobre um estrado de madeira entre dois canteiros, e de tensiômetros localizados a 0,15 e $0,30 \mathrm{~m}$ de profundidade, aproximadamente a $0,10 \mathrm{~m}$ de distância da planta e do gotejador. Assim, a lâmina de irrigação era calculada com base na evaporação do tanque "Classe A", estimada a partir da evaporação do tanque reduzido (Medeiros et al., 1997), assumindo Kp igual a 1,0 (Martínez-Raya \& Castilla, 1989; Castilla et al., 1990) e o ajuste era feito pela leitura do tensiômetro mais profundo nas parcelas que receberam a menor lâmina (L1). Quando no dia após a irrigação o tensiômetro indicava que a umidade a 0,30 m não havia atingido a capacidade de campo, o Kc para a próxima irrigação era aumentado, resultando no aumento da lâmina de irrigação. Para o cálculo da lâmina a ser aplicada considerou-se a área total do ambiente protegido e não apenas a área do canteiro; desta forma, a área ocupada por uma planta era de $0,40 \mathrm{~m}^{2}$, correspondendo a uma população de 25000 plantas ha-1.

O sistema de irrigação utilizado foi o gotejamento, com emissores de vazão média de $4,0 \mathrm{~L} \mathrm{~h}^{-1}$ e com um emissor por planta localizado a $2 \mathrm{~cm}$ de distância do colo das plantas. Os adubos foram misturados manualmente à água de irrigação, em caixas d'água de 500 L de capacidade. A água utilizada nas irrigações era de boa qualidade, proveniente da estação de tratamento de água da USP/ESALQ, a qual apresentava condutividade elétrica de $0,22 \mathrm{dS} \mathrm{m}^{-1}$ e $\mathrm{pH}$ de 8,1 .

Os adubos utilizados foram sulfato de amônio, nitrato de cálcio, ácido fosfórico, nitrato de potássio, cloreto de potássio e sulfato de magnésio, sendo que $1 / 4$ do $\mathrm{N}$ foi aplicado na forma de amônio e $3 / 4$ na forma de nitrato. $\mathrm{O}$ parcelamento da adubação durante o ciclo da cultura foi realizado conforme recomenda Papadopoulos (1994) e os fertilizantes foram adicionados à água em todas as irrigações. Como o solo apresentava altos teores de todos os nutrientes na ocasião do transplantio, não foi realizada adubação de fundação e a fertirrigação iniciou-se aos 19 dias após o transplantio (DAT). As quantidades de cada nutriente aplicadas via fertirrigação no tratamento $\mathrm{L}_{1}$, encontram-se na Tabela 2 e na Figura 1. Visto que a concentração de nutrientes na água de irrigação foi a mesma para todos os tratamentos, as parcelas que receberam $25 \%$ a mais de água $\left(\mathrm{L}_{2}\right)$ receberam também esta mesma porcentagem a mais de fertilizantes.

Foram determinados a produção comercial (PC), a produção total (PT), o número de frutos comerciais (NFC) e o número total de frutos (NTF) por planta e considerados frutos não comerciais ou refugo apenas aqueles excessivamente tortos ou mau formados.

Para se avaliar o risco de salinização do solo, coletaram-se amostras na profundidade de $0,20 \mathrm{~m}$, na linha de plantio, a $0,10 \mathrm{~m}$ de distância da planta. 
Tabela 2. Quantidade de N, P, K, Ca e Mg aplicada em cada fertirrigação, ao longo do ciclo da cultura de pepino, em ambiente protegido para o tratamento $\mathrm{L}_{1}$

\begin{tabular}{|c|c|c|c|c|c|c|}
\hline \multirow{2}{*}{ Fertirrigação } & \multirow{2}{*}{ DAT } & $\mathrm{N}$ & $\mathrm{P}$ & $\mathrm{K}$ & $\mathrm{Ca}$ & $\mathrm{Mg}$ \\
\hline & & \multicolumn{5}{|c|}{ g planta $^{-1}$} \\
\hline 1 & 19 & 0,264 & 0,039 & 0,361 & 0,244 & 0,010 \\
\hline 2 & 23 & 0,264 & 0,039 & 0,361 & 0,244 & 0,010 \\
\hline 3 & 27 & 0,211 & 0,031 & 0,289 & 0,196 & 0,008 \\
\hline 4 & 30 & 0,211 & 0,031 & 0,289 & 0,196 & 0,008 \\
\hline 5 & 34 & 0,381 & 0,034 & 0,397 & 0,265 & 0,014 \\
\hline 6 & 37 & 0,272 & 0,042 & 0,364 & 0,189 & 0,010 \\
\hline 7 & 40 & 0,328 & 0,030 & 0,346 & 0,228 & 0,012 \\
\hline 8 & 43 & 0,287 & 0,036 & 0,347 & 0,199 & 0,011 \\
\hline 9 & 46 & 0,305 & 0,032 & 0,339 & 0,212 & 0,012 \\
\hline 10 & 50 & 0,326 & 0,034 & 0,361 & 0,226 & 0,012 \\
\hline 11 & 52 & 0,226 & 0,036 & 0,307 & 0,157 & 0,009 \\
\hline 12 & 56 & 0,341 & 0,025 & 0,332 & 0,237 & 0,013 \\
\hline 13 & 59 & 0,296 & 0,038 & 0,360 & 0,206 & 0,011 \\
\hline 14 & 62 & 0,365 & 0,033 & 0,382 & 0,253 & 0,014 \\
\hline 15 & 65 & 0,355 & 0,041 & 0,410 & 0,247 & 0,013 \\
\hline 16 & 68 & 0,331 & 0,040 & 0,390 & 0,230 & 0,013 \\
\hline 17 & 71 & 0,335 & 0,037 & 0,380 & 0,233 & 0,013 \\
\hline 18 & 75 & 0,398 & 0,037 & 0,423 & 0,277 & 0,015 \\
\hline 19 & 78 & 0,452 & 0,044 & 0,489 & 0,314 & 0,017 \\
\hline 20 & 82 & 0,245 & 0,050 & 0,382 & 0,170 & 0,009 \\
\hline 21 & 86 & 0,381 & 0,032 & 0,380 & 0,266 & 0,014 \\
\hline 22 & 89 & 0,428 & 0,043 & 0,455 & 0,299 & 0,016 \\
\hline 23 & 92 & 0,534 & 0,048 & 0,546 & 0,374 & 0,020 \\
\hline 24 & 95 & 0,674 & 0,060 & 0,685 & 0,471 & 0,025 \\
\hline 25 & 98 & 0,581 & 0,076 & 0,694 & 0,406 & 0,022 \\
\hline 26 & 101 & 0,612 & 0,065 & 0,669 & 0,428 & 0,023 \\
\hline 27 & 105 & 0,542 & 0,069 & 0,639 & 0,379 & 0,020 \\
\hline 28 & 108 & 0,532 & 0,061 & 0,599 & 0,372 & 0,020 \\
\hline 29 & 111 & 0,371 & 0,060 & 0,492 & 0,259 & 0,014 \\
\hline 30 & 114 & 0,587 & 0,042 & 0,551 & 0,410 & 0,022 \\
\hline Total & - & 11,44 & 1,29 & 13,02 & 8,19 & 0,43 \\
\hline
\end{tabular}

\section{RESULTADOS E DISCUSSÃO}

A Tabela 3 apresenta os valores de Kc adotados em cada período do ciclo da cultura, a evaporação do tanque "Classe
A" no interior do ambiente protegido, estimada a partir da evaporação do tanque reduzido, e a lâmina de irrigação aplicada em cada tratamento por período. Os altos valores de Kc são devidos ao sombreamento do tanque pelas plantas, tornando necessário o aumento do valor deste coeficiente para que a lâmina de água de irrigação fosse suficiente para repor a evapotranspiração da cultura.

Tabela 3. Evaporação do tanque Classe A (ECA), valores médios adotados de Kc e lâmina de irrigação aplicada para diferentes intervalos de dias após o transplantio (DAT)

\begin{tabular}{ccrcc}
\multirow{2}{*}{ DAT } & \multirow{2}{*}{ Kc adotado } & \multirow{2}{*}{ ECA } & \multicolumn{2}{c}{ Lâmina de Irrigação no Período } \\
\cline { 3 - 5 } & & \multicolumn{3}{c}{$\mathrm{L}_{1}$} \\
\cline { 3 - 5 } & & \multicolumn{2}{c}{$\mathrm{mm}$} \\
\hline $19-32$ & 0,92 & 28,56 & 22,29 & 27,86 \\
$33-46$ & 1,22 & 20,02 & 24,12 & 30,15 \\
$47-60$ & 1,54 & 15,82 & 24,17 & 30,21 \\
$61-74$ & 1,50 & 20,02 & 30,31 & 37,89 \\
$75-88$ & 1,54 & 16,10 & 24,96 & 31,20 \\
$89-102$ & 1,52 & 27,86 & 39,53 & 49,41 \\
$103-114$ & 1,54 & 21,96 & 32,75 & 40,94 \\
Total & - & 150,34 & 198,13 & 247,66
\end{tabular}

A condutividade elétrica da água de irrigação (CEa) variou de 1,35 a 1,86 dS m $\mathrm{d}^{-1}$, sendo a CEa média de $1,58 \mathrm{dS} \mathrm{m}^{-1}$, e o pH de 5,7 a 7,3, com média de 6,5 (Fig. 2). As variações de $\mathrm{CEa}$ e pH foram, respectivamente, direta e inversamente proporcionais à quantidade de fertilizantes adicionada em cada fertirrigação. Verifica-se que a CEa foi praticamente constante ao longo do ciclo da cultura, embora o volume de água aplicado tenha aumentado consideravelmente no final do ciclo, indicando uma relação proporcional entre a necessidade hídrica e nutricional da cultura. Observa-se que, no final do ciclo de cultivo, a CEa apresentou ligeiro aumento, pois a redução da área foliar e, conseqüentemente, da ETc, resultante da senescência de folhas no final do ciclo, reduziu o volume de água aplicado nas irrigações; por outro lado, apesar da redução da área foliar, as plantas ainda apresentavam grande quantidade de frutos em

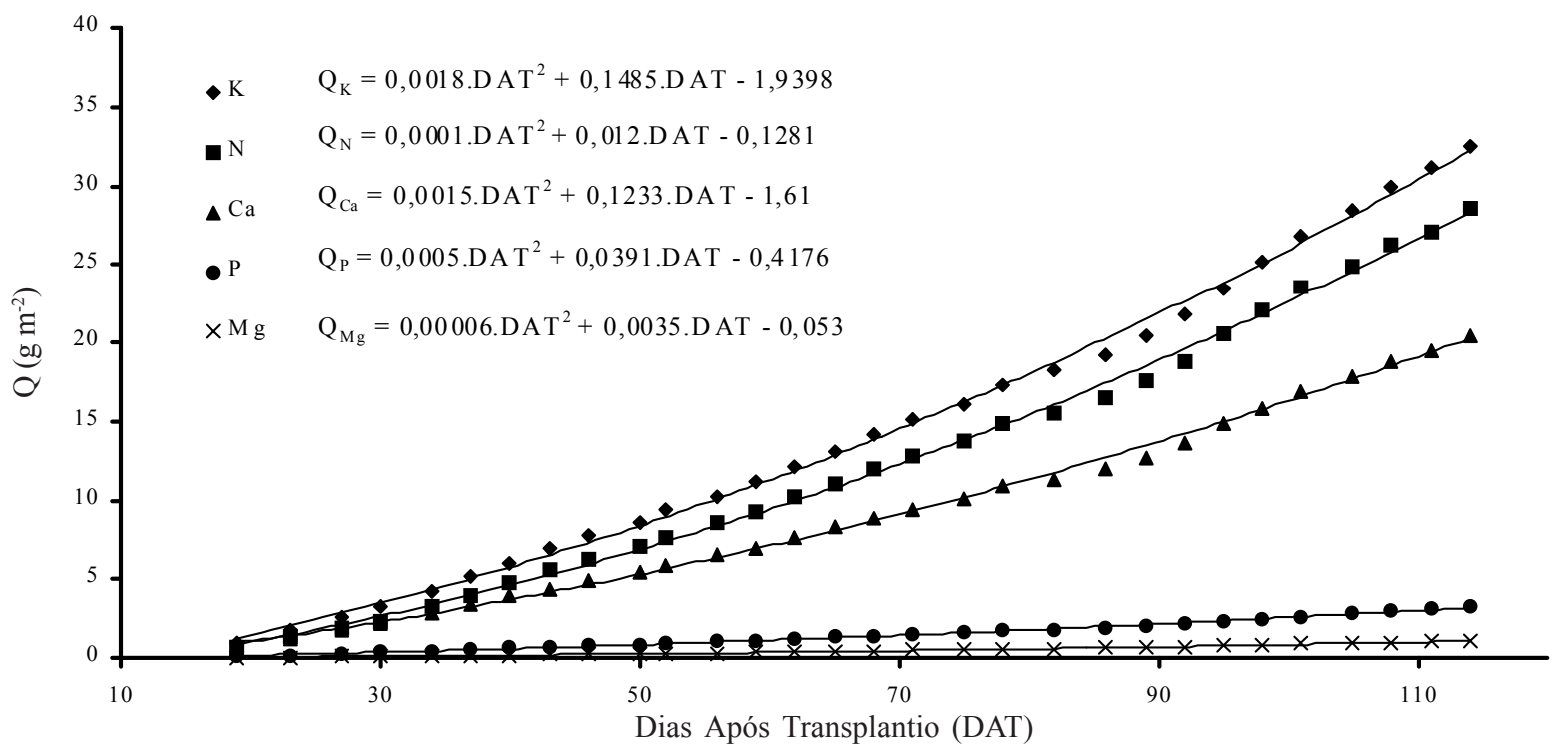

Figura 1. Quantidade acumulada (Q) em gramas por metro quadrado, de cada nutriente aplicado via fertirrigação, ao longo do ciclo da cultura de pepino em ambiente protegido, para o tratamento $\mathrm{L}_{1}$ 
desenvolvimento, fazendo com que a quantidade de fertilizantes adicionada à água de irrigação se mantivesse elevada.

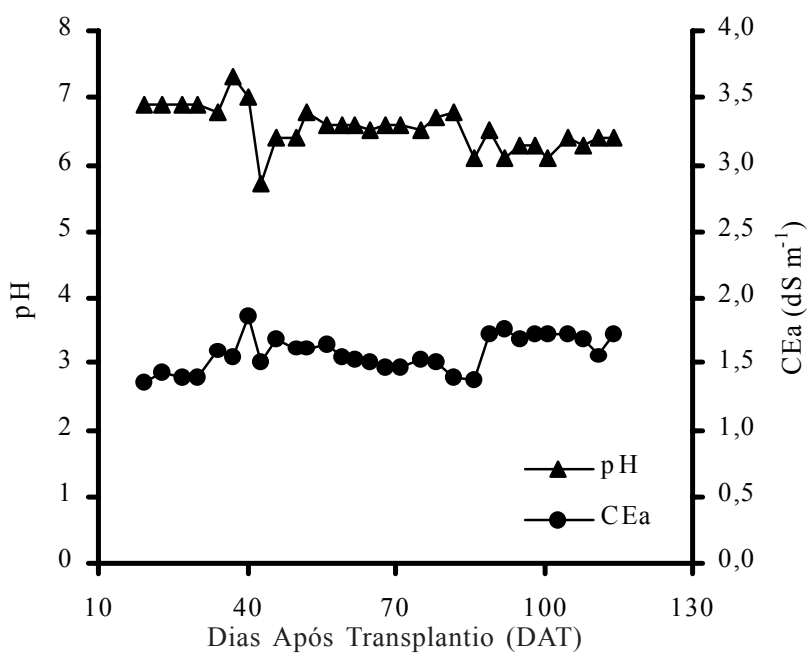

Figura 2. Condutividade elétrica (CEa) e pH da água de fertirrigação (água + fertilizantes) ao longo do ciclo do pepino em ambiente protegido

O potencial mátrico médio (média dos tensiômetros de 0,15 e $0,30 \mathrm{~m}$ ) no tratamento que recebeu a menor lâmina de irrigação $\left(\mathrm{L}_{1}\right)$ variou de $-48,7$ a $-2,4 \mathrm{kPa}$, com média de $-14,1 \mathrm{kPa}$ durante o período de cultivo. Para o tratamento que recebeu a maior lâmina $\left(\mathrm{L}_{2}\right)$, os potenciais mátricos, mínimo e máximo, foram, respectivamente, $-27,7$ e -2,4 $\mathrm{kPa}$, com média de $-6,4 \mathrm{kPa}$, indicando maior disponibilidade de água no solo neste tratamento, durante o ciclo da cultura (Fig. 3).

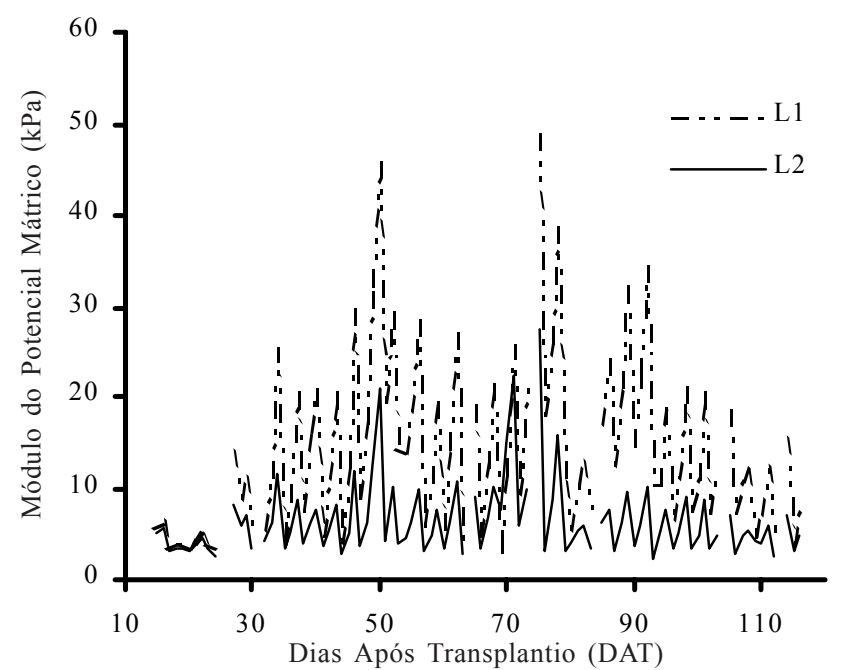

Figura 3. Módulo do potencial mátrico médio para as profundidades de 0,15 e $0,30 \mathrm{~m}$ para cada lâmina de irrigação utilizada

A maior disponibilidade hídrica no tratamento $\mathrm{L}_{2}$ não garantiu o aumento da produção, que foi praticamente igual àquela obtida para o tratamento $\mathrm{L}_{1}$ (Fig. 4); portanto, não se justifica a utilização de lâminas de irrigação elevadas e a conseqüente manutenção de alta umidade do solo, pois esta prática não resulta em maiores produções, podendo prejudicar a cultura devido ao excesso de água, e promover a lixiviação de nutrientes para profundidades que impeçam sua absorção pelas raízes, uma vez que a profundidade efetiva do sistema radicular das hortaliças se situa em torno de $0,20 \mathrm{~m}$.

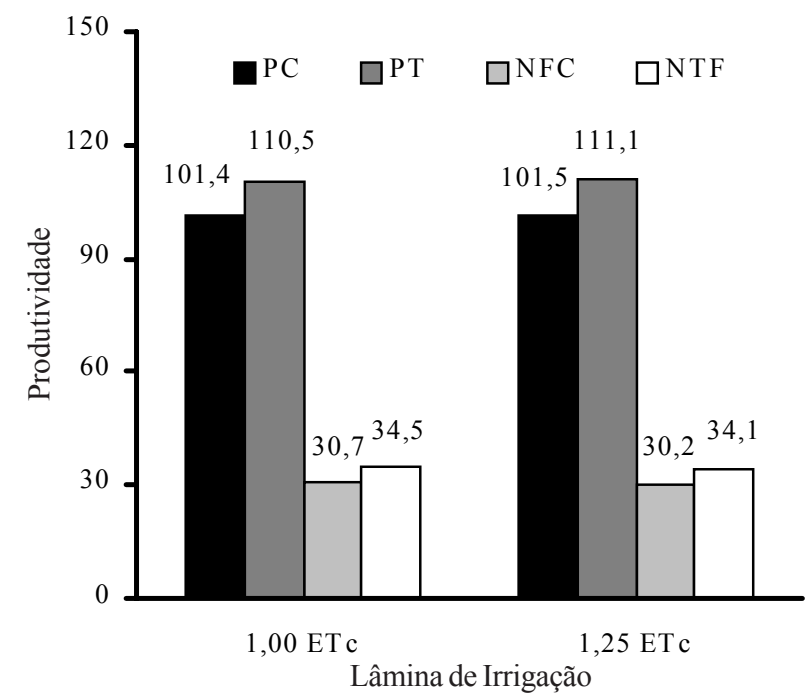

Figura 4. Produtividade comercial (PC) e total (PT), número de frutos comerciais (NFC) e número total de frutos (NTF) por planta de pepino em ambiente protegido para cada lâmina de irrigação

Como se pode observar, o manejo da fertirrigação utilizado neste trabalho resultou em produtividades acima de $100 \mathrm{Mg} \mathrm{ha}^{-1}$, bem superiores às obtidas pelos produtores do Estado de São Paulo, de 50 a $80 \mathrm{Mg} \mathrm{ha}^{-1}$, em média. Na Tabela 4 observa-se que a produtividade obtida neste estudo superou aquelas obtidas por diversos autores. Faria Jr. et al. (1998) embora tenham obtido PT de $12,93 \mathrm{~kg} \mathrm{~m}^{-2}$, a PC foi de $9,37 \mathrm{~kg} \mathrm{~m}^{-2}$, sendo esta, portanto, $8,4 \%$ inferior à $\mathrm{PC}$ obtida neste trabalho com o manejo da fertirrigação proposto. $\mathrm{O}$ elevado índice de frutos não comerciais (aproximadamente $28 \%$ da PT) pode ter sido ocasionado pelo esquema de adubação utilizado por este autor, visto que apenas o $\mathrm{N}$ foi aplicado em cobertura e os demais nutrientes aplicados em fundação, por ocasião da semeadura.

Observou-se aumento de salinidade no extrato de saturação de 1,70 para 2,28 $\mathrm{dS} \mathrm{m}^{-1}$ na $\mathrm{L}_{1}$ e de 1,53 para $2,07 \mathrm{dS} \mathrm{m}^{-1}$ na $\mathrm{L}_{2}$. Após cada ciclo de cultivo, para que não haja aumento apreciável da CEs, pode ser realizada periodicamente ou quando necessária a lavagem do solo, utilizando-se o próprio sistema de irrigação por gotejamento, como relatado por Blanco \& Folegatti (2001). Considerando que este aumento da salinidade do solo pode ter ocorrido devido ao resíduo de fertilizantes, alternativamente, a redução na dose aplicada de cada nutriente pode ser indicada visando o controle da salinidade e o uso eficiente de insumos.

\section{CONCLUSÕES}

1.A aplicação de uma lâmina de irrigação elevada manteve o potencial mátrico próximo à capacidade de campo, porém não resultou em aumento de produtividade. 
Tabela 4. Produtividades de pepino em ambiente protegido obtidas por diversos autores

\begin{tabular}{|c|c|c|c|c|c|c|c|c|c|}
\hline \multirow{2}{*}{ Cultivar/Híbrido } & \multicolumn{2}{|c|}{ PT } & \multicolumn{2}{|c|}{$\mathrm{PC}$} & \multicolumn{2}{|c|}{ NTF } & \multicolumn{2}{|c|}{ NFC } & \multirow{2}{*}{ Fonte } \\
\hline & $\mathrm{kg} \mathrm{planta}^{-1}$ & $\mathrm{~kg} \mathrm{~m}^{-2}$ & $\mathrm{~kg} \mathrm{planta}^{-1}$ & $\mathrm{~kg} \mathrm{~m}^{-2}$ & fr planta $^{-1}$ & fr $\mathrm{m}^{-2}$ & fr planta $^{-1}$ & fr $\mathrm{m}^{-2}$ & \\
\hline Hokuhoo & 2,12 & - & 1,97 & - & - & - & - & - & Carneiro Jr et al. (2000) \\
\hline Hokuhoo & - & - & - & - & - & 39,58 & - & 23,75 & Delmanto Jr \& Saad (2000) \\
\hline Hokushin & - & 12,93 & - & 9,37 & - & - & 23,90 & - & Faria Jr et al. (1998) \\
\hline Nikkey $^{*}$ & - & - & - & - & - & 48,60 & - & 29,10 & Cañizares \& Goto (1998) \\
\hline Ancor ${ }^{*}$ & - & - & - & - & - & 52,90 & - & 40,30 & Cañizares \& Goto (1998) \\
\hline Hokushin & 4,43 & 11,08 & 4,06 & 10,15 & 34,3 & 85,75 & 30,45 & 76,13 & Blanco (1999) \\
\hline
\end{tabular}

* Enxertado sobre abóbora, híbrido Ikki

PT: produção total; PC: produção comercial; NTF: número total de frutos; NFC: número de frutos comerciais

2. O manejo da fertirrigação utilizado permitiu a obtenção de alta produtividade do pepino enxertado, em ambiente protegido, podendo ser utilizada como referência na produção comercial ou experimental.

\section{AGRADECIMENTOS}

À Fundação de Amparo à Pesquisa do Estado de São Paulo, pela concessão dos recursos financeiros utilizados no desenvolvimento deste trabalho.

\section{LITERATURA CITADA}

Blanco, F.F. Tolerância do pepino enxertado à salinidade em ambiente protegido e controle da salinização do solo. Piracicaba: ESALQ/USP, 1999. 104p. Dissertação Mestrado

Blanco, F.F.; Folegatti, M.V. Recuperação de um solo salinizado após cultivo em ambiente protegido. Revista Brasileira de Engenharia Agrícola e Ambiental, Campina Grande, v.5, n.1, p.76-80, 2001.

Cañizares, K.A.L. A cultura de pepino. In: Goto, R.; Tivelli, S.W. (org.) Produção de hortaliças em ambiente protegido: condições subtropicais. São Paulo: Fundação Editora da UNESP, 1998. cap.7, p.195-223.

Cañizares, K.A.L.; Goto, R. Crescimento e produção de híbridos de pepino em função da enxertia. Horticultura Brasileira, Brasília, v.16, n.2, p.110-113, 1998.

Carneiro Junior, A.G.; Seno, S.; Ferreira Filho, H.F. Avaliação de cinco diferentes substratos para o cultivo de pepino fora do solo. Horticultura Brasileira, Brasília, v.18, p.494-495, 2000. Suplemento
Castilla, N.; Elias, F.; Fereres, E. Evapotranspiracion de cultivos horticolas en invernadero en Almeria. Investigacion Agraria: Produccion y Proteccion Vegetal, Madri, v.5, p.117-125, 1990.

Delmanto Jr, O.; Saad, J.C.C. Irrigação superficial e subterrânea por gotejamento na produção de pepino japonês conduzido em ambiente protegido. Horticultura Brasileira, Brasília, v.18, p.596-598, 2000. Suplemento

Faria Jr, M.J.A.; Araújo, J.A.C.; Castellane, P.D.; Seno, S. Híbridos de pepino cultivados em ambiente protegido, em abrigos com diferentes arquiteturas, em Ilha Solteira, SP. Cultura Agronômica, Ilha Solteira, v.7, n.1, p.81-90, 1998.

Martínez-Raya, A.; Castilla, N. Evapotranspiracion del pimiento en invernadero en Almeria. ITEA: Produccion Vegetal, Zaragoza, n.85, p.57-62, 1989.

Medeiros, J.F.; Pereira, F.A.C.; Folegatti, M.V.; Pereira, A.R.; Villa Nova, N.A. Comparação entre a evaporação em tanque Classe-A padrão e em minitanque, instalados em estufa e estação meteorológica. In: Congresso Brasileiro de Agrometeorologia, 10, 1997, Piracicaba. Anais... Piracicaba: SBA, 1997. p.228-230.

Papadopoulos, A.P. Growing greenhouse seedless cucumbers in soil and in soilless media. Ottawa: Agriculture and AgriFood Canada, 1994, 126p. Agriculture and Agri-Food Canada Publication, 1902/E

Papadopoulos, I. Fertirrigação: situação atual e perspectivas para o futuro. In: Folegatti, M.V. (coord.) Fertirrigação: citrus, flores, hortaliças. Guaíba: Agropecuária, 1999. cap.1, p.11-154.

Silva, W.L.C.; Carrijo, O.A.; Marouelli, W.A. Fertirrigação na EMBRAPA Hortaliças. In: Folegatti, M.V. (coord.) Fertirrigação: citrus, flores, hortaliças. Guaíba: Agropecuária, 1999. cap.5, p.433-440. 